D.O.I.:10.3895/S1808-04482006000200011

\title{
IDENTIFICAÇÃO DE SETORES PRODUTIVOS RELEVANTES COMO CONTRIBUIÇÃO AO EMPREENDEDORISMO E DESENVOLVIMENTO REGIONAL
}

\section{IDENTIFICATION OF IMPORTANTS PRODUCTIONS SECTORS FOR THE CONTRIBUTION THE REGIONAL DEVELOPMENT AND ENTREPRENEURS}

\author{
Vadson Bastos do Carmo ${ }^{1}$; Dra. Rosângela Maria Vannale ${ }^{2}$ \\ ${ }^{1}$ Faculdade de Tecnologia de São Paulo - FATEC-SP - Jundiaí - Brasil vadson@mpc.com.br \\ ${ }^{2}$ Universidade Metodista de Piracicaba - UNIMEP - Santa Bárbara D'oeste- Brasil \\ rvannale@unimep.br
}

\begin{abstract}
Resumo
Este artigo apresenta uma proposta de modelo para a identificação de setores produtivos relevantes de uma região como subsídio ao desenvolvimento de competências específicas $e$ empreendedorismo regional. O método proposto parte da identificação dos setores relevantes utilizando o Quociente Locacional, desenvolvido por Isnard, que considera o número de empresas e o número de empregos de um setor e compara com a quantidade total da região. Uma vez identificado estes setores produtivos, poderão ser mapeadas as competências relevantes $e$ desenvolvidas por meio de uma rede de apoio regional, incluindo universidades, centros de pesquisas, escolas técnicas, entidades de classe, sindicatos relacionados ao setor e empresários inclusos na cadeia produtiva, contribuindo assim, com o desenvolvimento regional.
\end{abstract}

Palavras chave: Empreendedorismo, Setores produtivos, Quociente Locacional.

\section{Empreendedorismo e desenvolvimento regional}

A introdução de um novo produto, método ou tecnologia, poderá ser estimulada se as competências necessárias forem identificadas e priorizadas nas suas gerações, incentivando o desenvolvimento de novos empreendedores, pesquisas e novas tecnologias que proporcionem o aumento da competitividade dos setores relevantes.

Nestas condições, as difusões da tecnologia para outros empreendimentos permitem o processo de acumulação, condição necessária, mas não suficiente para o desenvolvimento do sistema produtivo, sendo que, para o aumento da eficácia, é necessária uma ruptura radical que é dado por meio da introdução de um novo produto, método ou tecnologia, de maneira inovadora.

A teoria de Schumpeter, 1982, sobre o desenvolvimento econômico mostra que as mudanças podem ocorrer de maneira espontânea ou descontínua na estrutura produtiva existente. 
Quando as mudanças acontecem de maneira descontínua, ocorre pertubação do equilíbrio existente e conduz a economia a outras formas de comportamento, provocadas pelos grandes saltos das mudanças tecnológicas, desenvolvendo assim, a teoria dos ciclos, relacionada ao processo evolutivo do capitalismo, alternando em expansão e depressão, sendo que os períodos de expansão, quando do nascimento de novos empreendimentos e os de depressão, no final do processo de difusão das inovações, com maior concorrência e redução de custos, provocando a estagnação. (ARAÚJO, 1989)

Neste cenário, segundo a visão schumpeteriana, destaca-se o papel do agente transformador, do empreendedor, com função essencial no processo do desenvolvimento econômico, sendo o responsável pela operação de novas combinações dos fatores produtivos.

\section{Setores produtivos em aglomerados de pequenas empresas}

Até o fim da década de setenta, eram considerados como suportes econômicos, somente o Estado e as grandes empresas, porém a partir da década de oitenta, com o aumento significativo da utilização de tecnologia intensiva e o aumento da concorrência, em nível mundial, por meio da globalização de produtos e serviços, o Estado passa a ter dificuldade para cumprir seus compromissos e aumenta o seu endividamento, dificultando a geração de investimentos em infraestrutura e novos empregos.

Neste cenário, como alternativa, as pequenas empresas passaram a ter uma grande importância como fonte geradoras de novas oportunidades e empregos, para atender, não somente o mercado local, mais também o mercado internacional.

Para o estímulo ao desenvolvimento econômico e social de uma região, o empreendedorismo se mostra como um mecanismo acionador dos processos que deverão encadear uma série de ações e transformações, e que, muito provável, se iniciará por meio de pequenas empresas, sendo que, uma das características fundamentais, é a sua relação com a comunidade local, que poderá ser um catalisador do processo de desenvolvimento quanto melhor for o ambiente favorável ao empreendedorismo. (DOLABELA, 1999)

Segundo BENKO, 2002, o desenvolvimento local e regional necessita que as instituições da comunidade local tenham envolvimento participativo, desde a realização do diagnóstico e planejamento, até o controle e melhoria do sistema, passando pela elaboração de compromissos com o poder público e privado, no sentido do fortalecimento e fomento de uma sociedade e comunidade local mais pró-ativa e inovadora, através de uma integração com as IES, tendo como papel importante, a geração de conhecimento e tecnologia para o desenvolvimento e a diversificação da economia local em cadeias e redes produtivas empresariais, produzindo então, 
vantagens competitivas.

\section{Proposta de modelo para identificação de setores produtivos relevantes}

Partindo-se da teoria do Quociente Locacional desenvolvida originalmente por ISARD, 1960, que trata da identificação dos setores produtivos importantes de determinada região, por meio de um quociente que relaciona os setores que apresentam a maior quantidade de empresas e empregos em uma determinada região.

Então, para identificação dos setores produtivos pode-se aplicar o Q.L. (Quociente Locacional), índice de especialização, citado na literatura e amplamente utilizado em estudos de economia e de desenvolvimento regional. . A sua definição é:

$\underline{\mathrm{QL}} \mathrm{ij}=\mathrm{Eij} /$ Eoj $=$ Quociente Locacional do setor i na região $\mathrm{j}$

$$
\mathrm{Eoj} / \mathrm{Eoo}
$$

Sendo:

Eij = emprego no setor i da região j;

Eoj $=\sum \mathrm{i}$ Eij $=$ emprego em todos os setores da região $\mathrm{j}$;

Eio $=\sum \mathrm{jEij}=$ emprego no setor $\mathrm{i}$ de todas as regiões;

Eoo $=\sum \mathrm{i} \sum \mathrm{j}$ Eij $=$ emprego em todos os setores de todas as regiões

O QL indica a concentração relativa de uma determinada indústria numa região ou município, sendo que, um QL alto numa determinada indústria numa região ou município indica a especialização da estrutura de produção local ou regional.

A proposta de um modelo para a identificação de setores produtivos relevantes de uma região é mostrada na figura 1 abaixo:

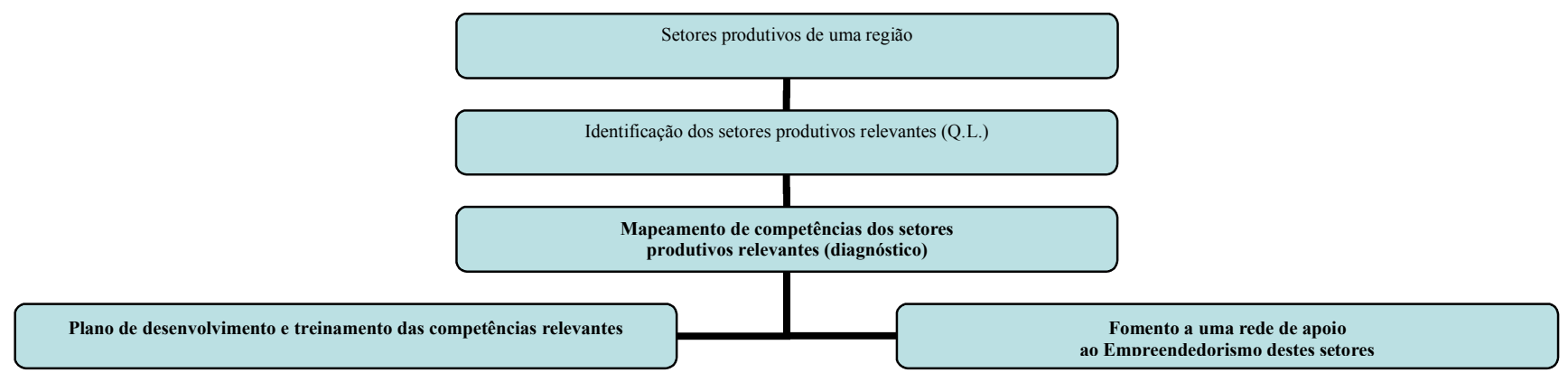

Figura 1: Proposta de modelo para identificação de setores produtivos relevantes

Aplicando-se este modelo, por exemplo, para o município de São Carlos, pode-se notar que 
o setor de indústrias de máquinas e equipamentos, possuí um Q.L. de 4,3 com relação ao número de empregos do setor em relação à região e um Q.L. 1,2 com relação ao número de empresas do setor em relação `a região, demonstrando um quociente locacional acima da média e caracteriza uma especialização territorial, ou seja, concentração de empresas e empregos neste setor, conforme mostrado nas tabelas 2 e 3 , a seguir:

Tabela 2: Quantidade de empregados no município de São Carlos fonte: Sebrae-SP, Perfil econômico regional

\begin{tabular}{|l|l|l|}
\hline $\begin{array}{l}\text { principais setores segundo } \\
\text { CNAE }\end{array}$ & $\begin{array}{l}\text { \% de empregados do setor } \\
\text { na região }\end{array}$ & $\begin{array}{l}\text { Q.L. } \\
\text { Quociente Locacional }\end{array}$ \\
\hline Ind. de máquinas e equipamentos & 11,2 & 4,3 \\
\hline Ind. De Alim. e Bebidas & 8,3 & 2,0 \\
\hline Ind. Min. não-metal. & 5,8 & 4,3 \\
\hline Ind. Móveis & 5,0 & 4,0 \\
\hline Ind. Têxtil & 3,5 & 1,4 \\
\hline Ind. Constr. Civil & 2,5 & 0,5 \\
\hline TOTAL INDÚSTRIA & $\mathbf{4 7 , 4}$ & $\mathbf{1 , 2}$ \\
\hline
\end{tabular}

Fonte: adaptado pelo autor

Tabela 3: Quantidade de empresas no município de São Carlos fonte: Sebrae-SP, Perfil econômico regional

\begin{tabular}{|l|l|l|}
\hline $\begin{array}{l}\text { principais setores segundo } \\
\text { CNAE }\end{array}$ & $\begin{array}{l}\text { \% de empresas do setor } \\
\text { na região }\end{array}$ & $\begin{array}{l}\text { Q.L. } \\
\text { Quociente Locacional }\end{array}$ \\
\hline Ind. Min. não-metal. & 4,0 & 4,5 \\
\hline Ind. Constr. civil & 2,8 & 0,7 \\
\hline Ind. Alim. e Bebidas & 2,1 & 1,4 \\
\hline Ind. Móveis & 1,7 & 1,5 \\
\hline Ind. Met. (não equip.) & 1,4 & 1,1 \\
\hline Ind. Máq. e Equipamentos & 0,9 & 1,2 \\
\hline TOTAL INDÚSTRIA & $\mathbf{1 9 , 0}$ & $\mathbf{1 , 0}$ \\
\hline
\end{tabular}

Fonte: adaptado pelo autor

Neste caso, seria priorizado, pela rede de apoio, os setores com os maiores quocientes locacionais, tanto em relação ao número de empresas, quanto em relação ao número de empregos, como o setor de indústria de máquinas e equipamentos, que apresenta um QL acima da média nesta região, podendo este setor ser priorizado como objeto de estudos e incentivos para o desenvolvimento de competências específicas para a geração de empreendedores, profissionais qualificados, pesquisas e inovação tecnológicas para este setor.

Este setor pode ser considerado muito importante na ótica do desenvolvimento capitalista atual, permitindo excelentes avanços de produtividade em diversos outros setores produtivos, pois, 
segundo CASTELLS, 1999, requer que sejam acolhidas condições relativas à oferta de alto potencial técnico e científico, por meio de excelentes instituições de ensino superior, centros de pesquisas e desenvolvimento de caráter público e privado, proporcionando meios inovadores para que o desenvolvimento produtivo ocorra.

\title{
4. Considerações finais
}

As transformações setoriais são explicadas por meio da instabilidade provocada pelas mudanças tecnológicas segundo as visões de desenvolvimento tecnológico e teoria de crescimento iniciada por Schumpeter, que acreditava que tais transformações eram exercidas por setores específicos.

Por outro lado, se o empreendedorismo pode ter uma relação direta com desenvolvimento regional, especialmente em setores relevantes, com uma quantidade acima da média do Quociente Locacional, identificar quais as competências necessárias para estes setores, poderá facilitar o processo de acumulação de tecnologia e geração de novos conhecimentos e empreendimentos para estes setores, proporcionando o desenvolvimento econômico.

Esta identificação facilitará a introdução de ações de desenvolvimento da cultura empreendedora, estimulando as organizações participantes da rede de apoio ao setor produtivo relevante da região, a produzirem conhecimentos, priorizarem seus recursos de forma a incentivarem o surgimento de novos profissionais, empreendedores e pesquisadores para estes setores produtivos.

\begin{abstract}
The objective of this document is the model of identification for the regional importants sectors wich support for the competences developments and the regional entrepreneurs. The metod suppose start in the identification of the importants sectors using the locacional quocient written of Isnard, wich to consider the number of the enterprises and the jobs of the sector and to compare wich the total quantity of the region. This competences could be development through of the regional support network wich universities, research centers, technical schools and trades union for the regional development.
\end{abstract}

Key-words: regional development, enterpreneur, locacional quocient.

\section{Referências}

ARAÚJO, J. D., "Padrões tecnológicos e transformação no setor leiteiro: uma abordagem schumpeteriana", Tese apresentada ao departamento de economia da Universidade Estadual de São Paulo para obtenção do título de doutor em economia, São Paulo, 1989.

BEDE, M.A, Subsídios para a identificação de clusters no Brasil, São Paulo: Sebrae, 2002 
BENKO, G.0, "Economia, espaço e globalização - na aurora do século XXI”, 3 a Ed., São Paulo: Hucitec \& Annablume, 2002

CASTELLS, M.; “A sociedade em rede”; trad. Roneide Venâncio Majer; São Paulo: Paz e Terra; v.1; 1999

DOLABELA, F.; “Oficina do Empreendedor: a metodologia de ensino que ajuda a transformar conhecimento em riqueza”; São Paulo: Cultura Editores Associados; 1999

DORNELAS, J. C. A., “Empreendedorismo - Transformando idéias em negócios”, Rio de Janeiro: Campus, 2001

DUTRA, J. S., Gestão por competências - um modelo avançado para o gerenciamento de pessoas, São Paulo: Editora Gente, 2001

FURTADO, C., "Introdução ao desenvolvimento: enfoque histórico-estrutural", $3^{\text {a }}$ Ed., Rio de Janeiro: Paz e Terra, 2000

HADDAD, P.R., "Medidas de Localização e de Especialização", in Haddad, P.R. (org.) Economia Regional: teorias e métodos de análise.Fortaleza, BNB-Etene, 1989.

ISARD, W., “ Methods of regional analysis”, Cambridge: MIT Press, 1960

MYTELKA, L., FARINELLI, F., Local Clusters, Innovation Systems and Sustained Competitiveness, Contrato BNDES/FINEP/FUJB - Arranjos e Sistemas Produtivos Locais e as Novas Políticas de Desenvolvimento Industrial e Tecnológico - Nota Técnica 5, Rio de Janeiro, IE/UFRJ, 2000

PETIT, P. , Struture and development of a knowledge based economy: the policy implications, 2000

PORTER, M., Competição = On Competition: estratégias competitivas essenciais, Rio de Janeiro: Campus, 1999

SEBRAE, N., Plano de prioridades Sebrae-Na: arranjos produtivos locais - variáveis determinantes, Www.reinvencao.sebrae.com.br

SEBRAE-SP, Perfil Econômico Regional-Regiões selecionadas do Estado de São Paulo-relatório de pesquisa, São Paulo: Sebrae-SP, 1998

SCHUMPETER, J. A.; Teoria do desenvolvimento econômico: uma investigação sobre lucros, capital, crédito, juro e o ciclo econômico; tradução de Maria Sílvia Possas; São Paulo

\section{Dados do primeiro autor:}

Nome completo: Vadson Bastos do Carmo

Filiação institucional: FATEC-SP - Faculdade de Tecnologia de Jundiaí -SP

Departamento: Logística e Informática com ênfase em negócios

Função ou cargo ocupado: Professor Universitário

Endereço completo para correspondência: Rua Antônio José Ribeiro Jr., 95 apto 104-A - Bonfim -

Campinas - São Paulo - CEP: 13070-728

Telefones para contato: (19) 9744-3892

e-mail: vadson@mpc.com.br

Recebido para publicação: 23/0l/2006

Aceito para publicação: 15/05/2006 